\title{
Highly efficient relief diffraction gratings inscribed on a chalcogenide bulk glass by a femtosecond laser
}

\author{
T. Kohoutek ${ }^{1}$, M. A. Hughes ${ }^{2}$, H. Kawashima ${ }^{1}$, M. Mastumoto ${ }^{3}$, T. Misumi ${ }^{3}$, T. Suzuki ${ }^{1}$ and Y. \\ Ohishi ${ }^{1, *}$ \\ ${ }^{1}$ Research Center for Advanced Photon Technology, Toyota Technological Institute, 2-12-1 \\ Hisakata, Tempaku, Nagoya 468-8511, Japan \\ 2 Advanced Technology Institute, University of Surrey, Guildford, Surrey GU2 7XH, UK \\ ${ }^{3}$ Furukawa Denshi Co., Ltd., 2-3-2, Marunouchi, Chiyoda-Ku, Tokyo 100-8370, Japan \\ * ohishi@toyota-ti.ac.jp; phone +81 052 809-1862; fax +81 052 809-1869
}

\begin{abstract}
Direct laser writing has been already demonstrated for the fabrication of under surface "buried" 3D mid-IR waveguides in chalcogenide glasses by employing a large photo-induced refractive index change in the features formed in the path of the focused beam from a short pulse laser. In this paper, we report on direct laser writing of relief diffraction gratings with periods of 6,14 and $24 \mu \mathrm{m}$ into the surface of $\mathrm{Ge}_{15} \mathrm{Ga}_{3} \mathrm{Sb}_{12} \mathrm{~S}_{70}$ chalcogenide glass by using a $800 \mathrm{~nm}$ Ti:saphire femtosecond pulse laser. The first order diffraction efficiency of the fabricated gratings was over $60 \%$ at $650 \mathrm{~nm}$. We have also fabricated a "composite" grating composed of three relief diffraction gratings inscribed in the same position, but with a mutual tilt. Composite grating provided complex multidirectional diffraction of the light in the accordance with geometrical arrangement and grating period of all the gratings inscribed. The fabrication was implemented on a computer controlled stage employing surface-to-beam alignment, laser power and raster pattern control. Pulse energies of $1.5,3.0$ and $4.5 \mu \mathrm{J}$ were used, resulting in channel widths of around 4,5 and $6 \mu \mathrm{m}$, respectively, and depths up to 1.7 $\mu \mathrm{m}$. We propose practical applications including surface relief diffraction micro-gratings at the ends of multimode chalcogenide optical waveguides or on the surfaces of bare core optical fibers used for chemical sensing.
\end{abstract}

Keywords: Direct laser writing, Diffraction gratings, Chalcogenide glasses

\section{INTRODUCTION}

Chalcogenide glasses are highly transparent infrared materials representing materials of choice in MIR optical and photonic devices [1-5]. Micro- and nano-patterning of chalcogenide glass (or thin film) based optical devices then plays an important role for further enhancement of their functionalities and applications. Micro-patterning of chalcogenide glasses can be realized by numerous techniques such as traditional mask-based, multi photon or direct UV lithography [6-8], holography [9, 10], nano imprint lithography employing hard or soft stamps [11-13], ink-printing [14] or laser writing [15-18]. Femtosecond direct laser writing (DLW) has been demonstrated as an effective tool for fabrication of chalcogenide 3D photonic crystals [16], under surface "buried" waveguides [17] or low loss 3D waveguides [18] in chalcogenide GLS glasses employing large photo-induced changes in the refractive index of the features inscribed using focused beam and high power density from a short pulse lasers. In our experiment we have chosen a chalcogenide glass with the composition of $\mathrm{Ge}_{15} \mathrm{Ga}_{3} \mathrm{Sb}_{12} \mathrm{~S}_{70}$. Ge-Ga-Sb-S glasses represent a non-toxic choice among thermally stable sulfur-based chalcogenide glasses with high durability for applications, e.g. as optical waveguides or fibers [19, 20].

In this paper, we report fs-laser fabrication of highly efficient - over $60 \%$ in the first diffraction order - relief diffraction gratings in the surface of a chalcogenide bulk glass. The fabrication involved local heating of the glass surface in the path of a focused $800 \mathrm{~nm}$ fs-laser beam and its evaporation. The benefits of fs-laser inscribing include its contactless, mask- and etching-free processing and precise sample-to-beam alignment due to the three axis computer positioning control. We suppose that the fs-laser writing in chalcogenide bulk glass surface would enable the patterning of microgratings integrated on the ends of buried optical waveguides or onto the surfaces of multi-mode optical fibers acting as low-loss and high efficiency dispersive optical elements.

Micro-Optics 2012, edited by Hugo Thienpont, Jürgen Mohr, Hans Zappe, Hirochika Nakajima, Proc. of SPIE Vol. 8428, 84281C · C 2012 SPIE · CCC code: 0277-786X/12/\$18 · doi: 10.1117/12.921381 


\section{EXPERIMENTAL DETAILS}

The experimental setup for laser writing consisted of a Ti:saphire operating at $800 \mathrm{~nm}$ with a repetition rate of $1 \mathrm{kHz}$ and a pulse duration $200 \mathrm{fs}$, see Fig. 1. A sample of $\mathrm{Ge}_{15} \mathrm{Ga}_{3} \mathrm{Sb}_{12} \mathrm{~S}_{70}$ glass, polished both sides, with a refractive index (n) = 2.244 at $1.54 \mu \mathrm{m}$, was placed on a computer controlled stabilized stage with independent motion in all axes. The inscription beam was aligned by means of a green laser with the same optical path. We used a 40x (NA=0.6) microscope objective to focus a beam at the surface of glass. The translation speed was fixed at $\sim 150 \mu \mathrm{m} / \mathrm{s}$. The focused spot size was estimated to be $1.5 \mu \mathrm{m}$, which meant each spot in the beam path received 10 pulses. Pulse energies of $1.5,3.0$ and $4.5 \mu \mathrm{J}$ were used, with diffraction periods of 6,14 and $24 \mu \mathrm{m}$, respectively.

We roughly estimated the widths of the lines at the surface to be about 4, 5 and $6 \mu \mathrm{m}$ from optical microscope images but more accurate measurements need to be done to determine the exact widths and depths of fabricated channels. Fabrication of the composite grating involved sequential inscription of all of the three gratings on the same area but with mutual tilt. First, we inscribed the grating with $(\mathrm{d})=24 \mu \mathrm{m}$ and then the gratings with $(\mathrm{d})=14$ and $6 \mu \mathrm{m}$ together with mutual tilt of $52^{\circ}$ and $118^{\circ}$ against the grating with $(\mathrm{d})=24 \mu \mathrm{m}$. Figure 2 shows optical microscope images of the relief diffraction gratings inscribed into the surface of chalcogenide glass.

We observed diffraction patterns from the gratings in transmission mode, as shown in Fig. 3, for a red $650 \mathrm{~nm}$ laser at normal light incidence from the back side of the glass disc. The screen was at a distance (l) $=20 \mathrm{~cm}$ from the grating. We also measured power of the laser in front of the grating and laser power behind the grating for zero and $+/-1,2$ and 3 diffraction orders, respectively. In this case, the grating-to-powermeter distance was (l) $=30 \mathrm{~cm}$ in order to separate diffracted light spots. We added an aperture with the diameter of $5 \mathrm{~mm}$ in front of the power meter to measure the light power only of selected diffraction maximum (spot). Ambient light (background) in the dark room was $0.07 \mathrm{~mW}$ nearly negligible in comparison with the measured values.



Figure 1. Experimental setup used for direct laser writing of relief diffraction gratings into the surface of chalcogenide $\mathrm{Ge}-\mathrm{Ga}-\mathrm{Sb}-\mathrm{S}$ glass. The inset picture shows the glass disc with inscribed gratings. 

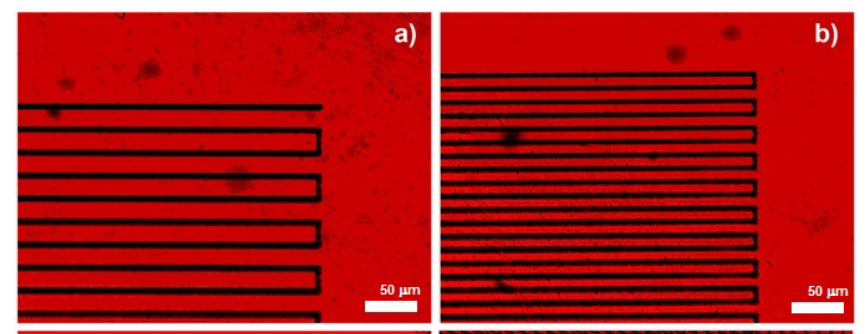

c)

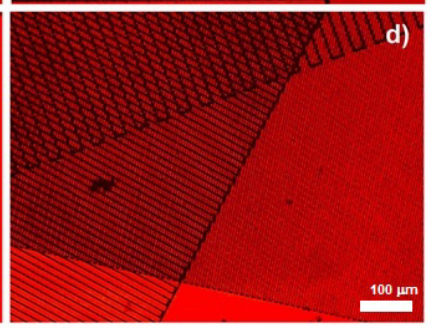

Figure 2. Optical microscope images (transmission mode) show the relief diffraction gratings inscribed into the surface of chalcogenide Ge-Ga-Sb-S glass with the period of $d=24 \mu \mathrm{m}(\mathrm{a}), \mathrm{d}=14 \mu \mathrm{m}(\mathrm{b}), \mathrm{d}=6 \mu \mathrm{m}$ (c) and composite grating (d), respectively.

\section{RESULTS AND DISCUSSION}

Figure 3 shows photographs (exposure time $(\mathrm{t})=3 \mathrm{~s}$ ) of diffraction patterns recorded from gratings illuminated with a $650 \mathrm{~nm}$ light at $\alpha=0^{\circ}$ for $\mathrm{d}=24,14,6$ and composite grating (a-d), respectively. Differences in the positions (pitch of the spots) of the diffraction maxima reflects the grating period (GP), defined as GP $=1$ / grating resolution (GR in $1 / \mathrm{mm}$ ), of each grating. The smaller period of the grating, the larger pitch on the screen for a given distance, as defined by the diffraction equation: $m \cdot \lambda=\Lambda$ ( $\left.\sin \Theta_{\mathrm{i}}+\sin \Theta_{\mathrm{D}, m}\right)$, where $m$ is the m'th diffraction order, $\lambda$ is the wavelength of the incident light, $\Lambda$ is the grating period, $\Theta_{\mathrm{i}}$ is the angle of incidence of the light, $\Theta_{\mathrm{D}, m}$ is the angle of diffraction for the $m$ 'th order. The composite grating showed multidirectional diffraction patterns reflecting the tilt of inscription of each single grating. We could also observe that each diffraction maximum was a "source" of another multidirectional diffraction, so the diffraction from 3-in-1 grating was then very complex. In the intermediate step of fabrication of the composite grating, i.e. after inscription of $(\mathrm{d})=24 \mu \mathrm{m}$ and $(\mathrm{d})=14 \mu \mathrm{m}$ gratings, we could observe only two directional diffraction looking similar like simple diffractions from these two gratings just overlapped with the center at the zero diffraction point.

In Fig. 4, the (grey) lines show the calculated diffraction of $650 \mathrm{~nm}$ light transmitted through a grating with $\mathrm{d}=6 \mu \mathrm{m}$. The incident angle of the beam was $\Theta_{\mathrm{i}}=0^{\circ}$ and the screen-grating distance (l) $=20 \mathrm{~cm}$. The spots (red in Fig. 3) on the screen correspond to measured positions of the diffracted light from the grating with $(\mathrm{d})=6 \mu \mathrm{m}$ being a part of the composite grating. On the right side in Fig. 4, the thicker (red) columns show measured values of the light power diffracted from the $(\mathrm{d})=6 \mu \mathrm{m}$ component of the composite grating, for three diffraction orders recorded at $(1)=30 \mathrm{~cm}$. For comparison, the thinner (blue) columns show measured light power of five diffraction orders for (d) $=6 \mu \mathrm{m}$ single grating at the same conditions.

Measured values of the light power for a $650 \mathrm{~nm}$ laser transmitted through the gratings at $(1)=30 \mathrm{~cm}$ and $\Theta_{\mathrm{i}}=0^{\circ}$ respecting the geometry depicted in Fig. 4, are summarized in Table 1. The power of laser light in font of the sample was $(\mathrm{P})=290 \mathrm{~mW} .(\mathrm{P})=272 \mathrm{~mW}$ was recorded as the light passed through a $1.5 \mathrm{~mm}$ thick Ge-Ga-Sb-S glass slice (bare sample without any grating), which represents the attenuation of the power of about $6.2 \%$, i.e. only by the glass itself. In Table 1, we can find laser power values measured for zero and $+/-1,2$ and 3 diffraction orders for prepared single gratings and compare them with the values recorded for the same grating but being a part of the composite grating. For them, the light power was measured for zero and $+/-1$ and 2 diffraction orders. 


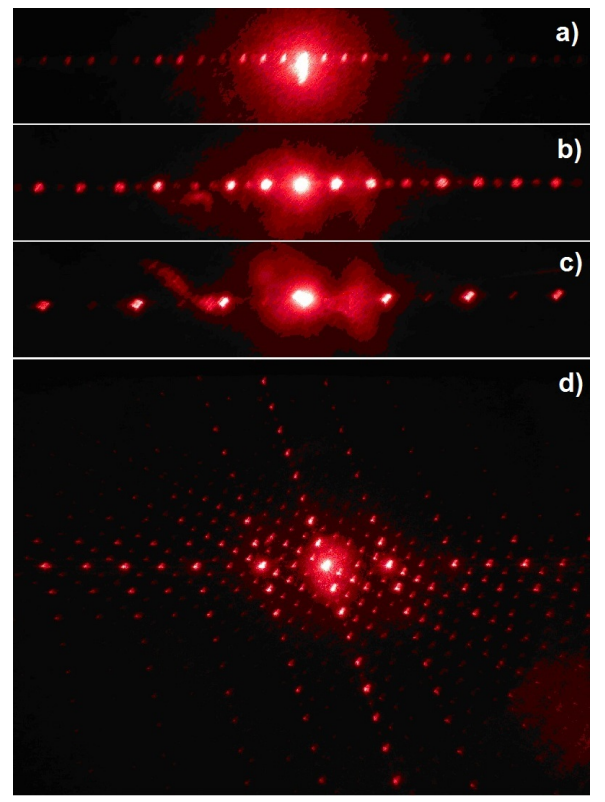

Figure 3. Diffraction patterns observed from gratings with $d=24 \mu \mathrm{m}, \mathrm{d}=14 \mu \mathrm{m}, \mathrm{d}=6 \mu \mathrm{m}$ (a-c) and composite grating (d) in transmission mode and for $650 \mathrm{~nm}$ laser.

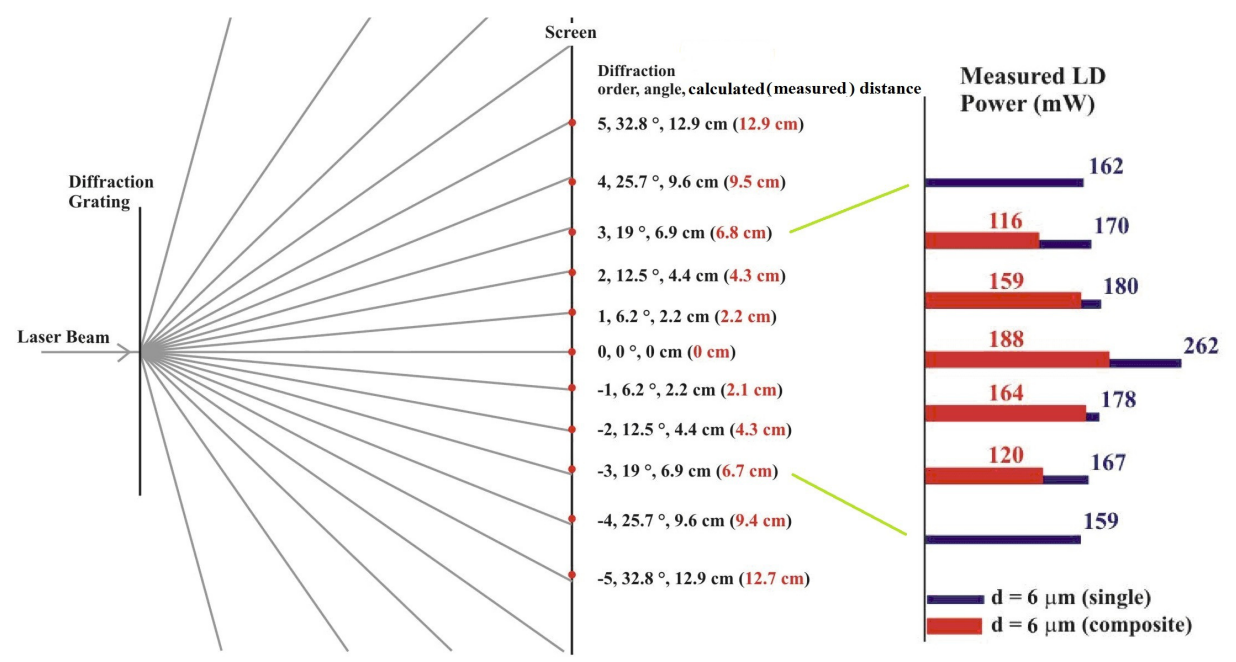

Figure 4. Lines show calculated diffraction of $650 \mathrm{~nm}$ light transmitting a grating with $\mathrm{d}=6 \mu \mathrm{m}$. The beam incidence was $\Theta_{\mathrm{i}}=0^{\circ}$ and the screen-to-grating distance $1=20 \mathrm{~cm}$. Spots on the screen correspond to measured diffraction from the $\mathrm{d}=6$ $\mu \mathrm{m}$ component of the composite grating. On the right, thicker columns show values of the light power diffracted from the $\mathrm{d}$ $=6 \mu \mathrm{m}$ component of the composite grating, recorded at $1=30 \mathrm{~cm}$, in comparison with the single grating $(\mathrm{d}=6 \mu \mathrm{m}$, thinner columns).

The diffraction efficiency $(\eta)$ of a grating represents a ratio of measured light power for $m$ 'th diffraction order to the light power in front of the grating (incident beam), i.e. $\left(\eta_{\mathrm{m}}\right)=\mathrm{P}_{\mathrm{D}, m} / \mathrm{P}_{\mathrm{i}}$. As apparent from values shown in Table 1, diffraction efficiency of single gratings (average values for $+/-m^{\prime}$ th order) reached $\left(\eta_{+/-1, \text { ave }}\right)=61.72 \%$ for single grating with $(\mathrm{d})=$ $6 \mu \mathrm{m},\left(\eta_{+/-1, \text { ave }}\right)=67.76 \%$ for single grating with $(d)=14 \mu \mathrm{m}$, and $\left(\eta_{+-1, \text { ave }}\right)=60.86 \%$ for single grating with $(d)=24$ $\mu \mathrm{m}$, respectively. Similarly, efficiency values $\left(\eta_{+/ 2,2}\right.$ ave $)$ for the same gratings were $58.10,52.24$ and $55.17 \%$, respectively. For single gratings $\eta$ values remained similar with the manner of inaccuracy of the measurement (approx. 5). Corresponding $\left(\eta_{+/-1, \text { ave }}\right)$ values were calculated for diffraction gratings being a part of composite grating, i.e. $55.69 \%$ $((\mathrm{d})=6 \mu \mathrm{m}), 47.07 \%((\mathrm{~d})=14 \mu \mathrm{m})$ and $30.34 \%((\mathrm{~d})=24 \mu \mathrm{m})$. The diffraction efficiency in this case decreased with increasing $d$ of a grating, which may be an effect attributed to strong wavelength preferential diffraction, i.e. we expect increase of $(\eta)$ values for larger (d) with increasing $(\lambda)$ and vice versa. 
Table 1. Measured transmitted power of $650 \mathrm{~nm}$ light at the distance of $1=30 \mathrm{~cm}$ from diffraction gratings. The light beam incident angle was $\Theta_{\mathrm{i}}=0^{\circ}$. The power of laser light without any sample was $\mathrm{P}=290 \mathrm{~mW} . \mathrm{P}=272 \mathrm{~mW}$ was recorded after a $1.5 \mathrm{~mm}$ thick glass slice on which the gratings were inscribed representing the attenuation of the power of about $6.2 \%$.

\begin{tabular}{|c|c|c|c|c|c|}
\hline \multicolumn{6}{|c|}{ Measured power of $650 \mathrm{~nm} L D$ recorded at the distance $l=30 \mathrm{~cm}$} \\
\hline \multicolumn{2}{|c|}{$\mathrm{d}=6 \mu \mathrm{m}$ (single) } & \multicolumn{2}{|c|}{$\mathrm{d}=14 \mu \mathrm{m}$ (single) } & \multicolumn{2}{|c|}{ 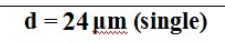 } \\
\hline \multicolumn{2}{|c|}{ Order / Power $(\mathrm{mW})$} & \multicolumn{2}{|c|}{ Order / Power $(\mathrm{mW})$} & \multicolumn{2}{|c|}{ Order / Power $(\mathrm{mW})$} \\
\hline \multicolumn{2}{|c|}{$0(262)$} & \multicolumn{2}{|c|}{$0(242)$} & \multicolumn{2}{|c|}{$0(250)$} \\
\hline$-1(178)$ & $1(180)$ & $-1(193)$ & $1(200)$ & $-1(175)$ & $1(178)$ \\
\hline$-2(167)$ & $2(170)$ & $-2(149)$ & $2(154)$ & $-2(158)$ & $2(162)$ \\
\hline \multirow[t]{2}{*}{$-3(159)$} & $3(162)$ & $-3(91)$ & $3(94)$ & \multirow[t]{2}{*}{$-3(137)$} & $3(140)$ \\
\hline & & $-4(129)$ & $4(135)$ & & \\
\hline \multicolumn{2}{|c|}{$\begin{array}{c}\mathrm{d}=\mathbf{6 \mu \mathrm { m }} \\
\text { in composite DG }\end{array}$} & \multicolumn{2}{|c|}{$\begin{array}{c}d=14 \mu \mathrm{m} \\
\text { in composite DG }\end{array}$} & \multicolumn{2}{|c|}{$\begin{array}{c}d=24 \mu \mathrm{m} \\
\text { in composite DG }\end{array}$} \\
\hline \multicolumn{2}{|c|}{ Order / Power (mW) } & \multicolumn{2}{|c|}{ Order / Power (mW) } & \multicolumn{2}{|c|}{ Order / Power (mW) } \\
\hline \multicolumn{2}{|c|}{0 (188) } & \multicolumn{2}{|c|}{0 (188) } & \multicolumn{2}{|c|}{0 (188) } \\
\hline$-1(159)$ & $1(164)$ & $-1(135)$ & $1(138)$ & $-1(86)$ & $1(90)$ \\
\hline$-2(116)$ & $2(120)$ & $-2(81)$ & $2(84)$ & $-2(40)$ & 2 (44) \\
\hline
\end{tabular}

We propose some applications of DLW relief diffraction gratings in Fig. 5. The micro-gratings can be used as dispersive optical elements inscribed at the ends of waveguides $(a, b)$ or onto the surface of optical fiber cores (c). In these applications, the contactless, mask-free and of DLW can be exploited. The micro-gratings then could provide high efficiency and low loss operation since they are integrated in the optical components.

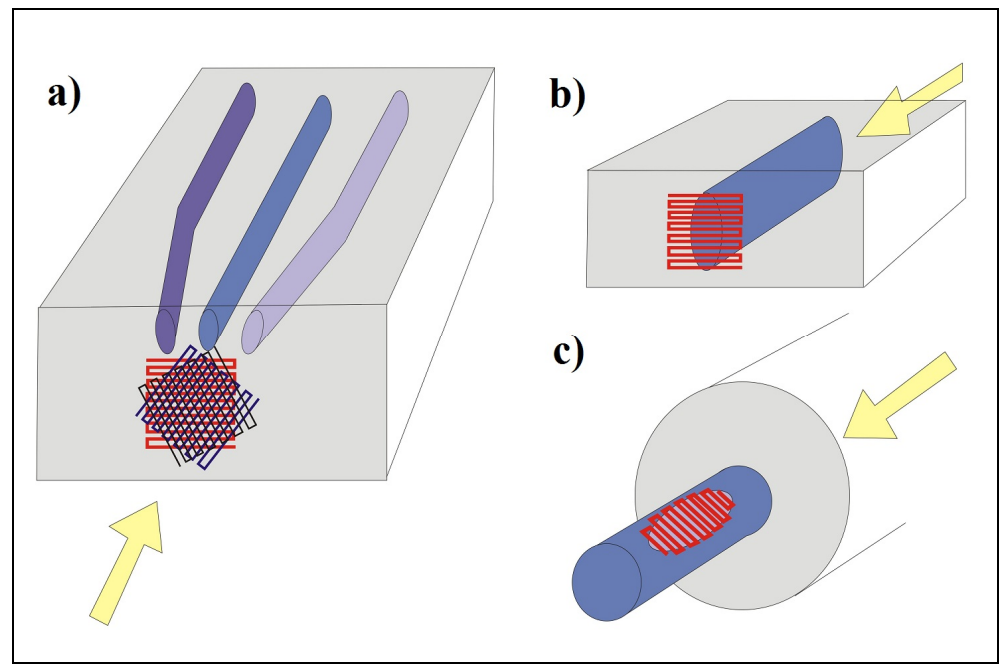

Figure 5. Laser writing permits a contactless fabrication of diffraction gratings inscribed at the end of optical waveguides (a, b) or in a bare fiber core (c) used for sensing applications (the arrows show an intended beam input).

In DLW, femtosecond lasers may have several advantages over conventional laser systems for the micro-machining of glasses. Firstly, the occurrence of breakdown events at the breakdown threshold for fs pulse ablation of glasses has much less statistical variability than for longer pulse durations [21]. This is related to different physical mechanisms for breakdown being involved at ultrashort pulse widths and it results in a well defined ablation threshold which allows subdiffraction limited ablation to occur [22-24]. For longer pulses a large volume is heated and melted then expelled by the vapor pressure, this is an unstable process driven by complex fluid dynamics and in micromachining applications it can lead to irregular shapes in holes and cuts. However, in ultrashort pulses material is removed by direct vaporization away from the sample and the heat affected volume is much smaller (not negligible) due to the short interaction time, leading to precisely machined cuts with reduced collateral damage [25]. If the repetition rate of the fs pulses exceeds $\sim 200 \mathrm{kHz}$, heat accumulation can extend the heat affected zone well beyond the focal volume [26] (not applicable in our case since we used a $1 \mathrm{kHz}$ repletion rate). Recently, it was reported DLW with system operating with $\sim 25 \mathrm{fs}$ pulses and $<1 \mu \mathrm{J}$ laser 
pulse power densities that provided enhancements in reduction of roughness of the inscribed features leading to fabrication of highly efficient low loss optical devices, e.g. in [18].

\section{CONCLUSIONS}

In this paper, we showed direct laser writing of relief diffraction gratings with periods of 6,14 and $24 \mu \mathrm{m}$ onto the surface of $\mathrm{Ge}_{15} \mathrm{Ga}_{3} \mathrm{Sb}_{12} \mathrm{~S}_{70}$ chalcogenide glass by using a $800 \mathrm{~nm}$ Ti:saphire femtosecond pulse laser. The first order diffraction efficiency of the fabricated gratings was over $60 \%$ at $650 \mathrm{~nm}$ with transmission operation at $\Theta_{\mathrm{i}}=0^{\circ}$. We are currently working on characterization of these gratings by using near-infrared lasers. We assume that appropriately designed transmission diffraction gratings inscribed onto the surface of chalcogenide glasses can preserve high diffraction efficiency over nearly the entire range of their transparency which extends to mid-IR, e.g. Ge-Ga-Sb-S glass has transparency window $0.58-12 \mu \mathrm{m}$. We have also shown a composite grating and its complex diffraction pattern that can be a good choice for optimalization of diffraction in the wide range of IR wavelengths because smaller grating periods can be more efficient for shorter wavelength diffraction while larger grating periods can be more efficient for

longer wavelength diffraction. The surface relief micro-gratings could be also a good choice as low-loss dispersive optical elements when fabricated on the end of buried IR waveguides or onto the surfaces of bare core sensing fibers.

\section{REFERENCES}

[1] R. W. Waynant, I. K. Ilev, and I. Gannot, Phil. Trans. R. Soc. Lond. Ser. A 359, 635 (2001).

[2] F. K. Tittel, D. Richter, and A. Fried, in Solid-State Mid-Infrared Laser Sources, I. T. Sorokina and K. L. Vodopyanov, eds., Topics in Applied Physics, Vol. 89 (Springer-Verlag, 2003), pp. 445-516.

[3] R. Muda, E. Lewis, S. O’Keeffe, G. Dooly, and J. Clifford, Phys. Conf. Ser. 178, 012008 (2009).

[4] D. Ouzounov and F. Freund, Adv. Space Res. 33, 268 (2004).

[5] L. Labadie and O. Wallner, Opt. Express 17, 1947 (2009).

[6] Yasushi Utsugi and Sakae Zembutsu, Appl. Phys. Lett. 27, 508 (1975).

[7] M. Thiel, P. Brodersen, D. Fenske, G. A. Ozin, M Wegener, and G. von Freymann, Chem. Mater. (2007), 19(17), 4213.

[8] R. M. Bryce, H. T. Nguyen, P. Nakeeran, R. G. DeCorby, P. K. Dwivedi, C. J. Haugen, J. N. McMullin, and S. O. Kasap, J. Vac. Sci. Technol. A 22, 1044 (2004).

[9] J. M. Gonzalez-Leal, P. Krecmer, J. Prokop, and S. R. Elliott, J. Non-Cryst. Solids 326, 416 (2003).

[10] L. Su, C. J. Rowlands, and S. R. Elliott, Opt. Lett. 34(11), 1645 (2009).

[11]Z. G. Lian, W. Pan, D. Furniss, T. M. Benson, A. B. Seddon, T. Kohoutek, J. Orava, and T. Wagner, Opt. Lett. 34(8), 1234 (2009).

[12] J. Sanghera, C. Florea, L. Busse, B. Shaw, F. Miklos, and Ishwar Aggarwal, Opt. Express 18(25), 26760 (2010).

[13] J. Orava, T. Kohoutek, A. L. Greer, and H. Fudouzi, Opt. Mater. Express 1(5), 796 (2011).

[14]E. A. Sanchez, M. Waldmann, and C. B. Arnold, Appl. Opt. 50(14), 1974 (2011).

[15] K. Miura, J. R. Qiu, H. Inouye, T. Mitsuyu, and K. Hirao, 239(1-3), 91 (1998).

[16] S. Wong, M. Deubel, F. Pérez-Willard, S. John, G. A. Ozin, M. Wegener, and G von Freymann, Adv. Mater, 18, 265 (2006).

[17] M. Hughes, W. Yang, and D. Hewak, Appl. Phys. Lett. 90, 131113 (2007).

[18] A. Ródenas, G. Martin, B. Arezki, N. Psaila, G. Jose, A. Jha, L. Labadie, P. Kern, A. Kar, and Robert Thomson, Opt. Lett. 37(3), 392 (2012).

[19] L. Brilland, F. Smektala, G. Renversez, T. Chartier, J. Troles, T. Nguyen, N. Traynor, and A. Monteville, Opt. Express 14, 1280 (2006).

[20] T. Kohoutek, X. Yan, T. W. Shiosaka, A. Chrissanthopoulos, S.N. Yannopoulos, T. Suzuki, Y. Ohishi, J. Opt. Am. Soc. B: Opt. Phys. 28(9), 2284 (2011).

[21] X. Liu, D. Du, and G. Mourou, IEEE J. Quantum Electron. 33, 1706-1716 (1997).

[22]F. Korte, S. Adams, A. Egbert, C. Fallnich, A. Ostendorf, S. Nolte, M. Will, J.-P. Ruske, B. Chichkov, and A. Tuennermann, Opt. Express 7, 41-49 (2000).

[23] S. Nolte, B. N. Chichkov, H. Welling, Y. Shani, K. Lieberman, and H. Terkel, Opt. Lett. 24, 914-916 (1999).

[24] P. P. Pronko, S. K. Dutta, J. Squier, J. V. Rudd, D. Du, and G. Mourou, Opt. Commun. 114, 106 (1995).

[25]B. C. Stuart, M. D. Feit, A. M. Rubenchik, B. W. Shore, and M. D. Perry, Phys. Rev. Lett. 74, 2248 (1995).

[26] S. M. Eaton, H. B. Zhang, and P. R. Herman, Opt. Express 13, 4708-4716 (2005).

Proc. of SPIE Vol. 8428 84281C-6 